\title{
1924
}

\section{LEMEBEL, EL}

NEOBARROCO Y LA

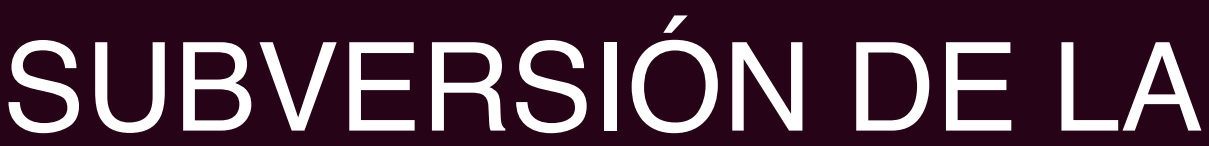

LENGUA: TENGO

MIEDO TORERO

CONTRA EL

DISCURSO DE LA

TRANSICIÓN CHILENA

Rodrigo Andrés Castro Rodríguez

Universitat de Barcelona

Ilustración || Riyoung Han

Artículo || Recibido: 14/03/2020 | Apto Comité Científico: 10/11/2020 | Publicado: 01/2021

DOI: 10.1344/452f.2021.24.11

rscastro@uc.cl

Licencia || Reconocimiento-No comercial-Sin obras derivadas 3.0 License 


\section{$452^{6} \mathrm{~F}$}

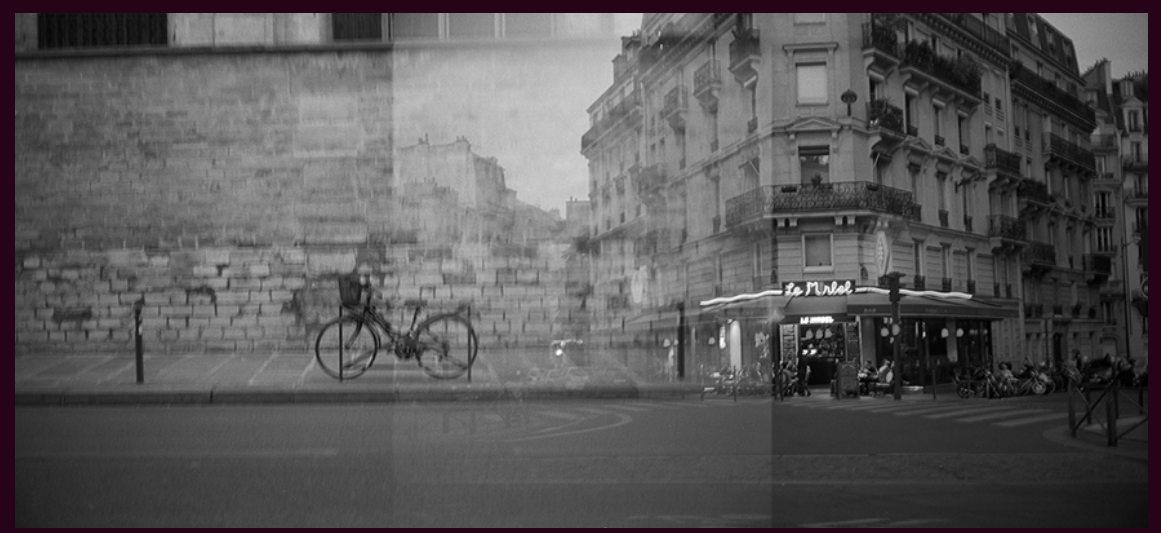

Resumen || En este artículo se analiza la novela de Pedro Lemebel Tengo miedo torero entendiéndola como una crítica a la transición chilena a la democracia. Para esto, se lee el texto desde los postulados neobarrocos del escritor y crítico cubano Severo Sarduy, que permiten pensar la subversión del lenguaje como una forma de reivindicación política. En el caso de la novela, esta crítica supone demostrar que la sociedad aún habla los mismos lenguajes de la dictadura, y para la liberación tanto sexual como política, es necesario poner las palabras en crisis. Desde el personaje de la Loca, se piensa la homosexualidad desde una diferencia que no cabe en los discursos que el lenguaje de la dictadura ha legado a la democracia, y así se desmantela poco a poco el discurso de unidad y optimismo de esos años.

\section{Palabras clave || Lemebel | Sarduy | Neobarroco | Lenguaje | Diferencia | Transición}

Abstract || This article analyzes the novel Tengo miedo torero by Pedro Lemebel understanding it as a criticism of the Chilean transition to democracy. With this aim, the text is read through the neo-baroque postulates of the Cuban writer and critic Severo Sarduy, which allow us to think of criticism of language as a form of political demand. In the case of the novel, this criticism is articulated through the demonstration that society still speaks the same languages of the dictatorship, and in order to achieve sexual and political liberation, it is necessary to put words themselves in crisis. Through the character of «la Loca», homosexuality is thought as a difference that exceeds the discourses that the language of dictatorship has bequeathed to democracy, and the prevailing discourse of unity and optimism of those years is gradually dismantled.

\section{Keywords || Lemebel | Sarduy | Neo-baroque | Language | Difference | Transition}

Resum || En aquest article s'analitza la novel-la de Pedro Lemebel Tengo miedo torero, entenent-la com una crítica a la transició xilena a la democràcia. Per a això, es llegeix el text des dels postulats neobarrocs del cubà Severo Sarduy, que permeten pensar la subversió del llenguatge com una forma de reivindicació política. En el cas de la novel-la, aquesta crítica suposa demostrar que la societat encara parla els mateixos llenguatges de la dictadura, i per a l'alliberament tant sexual com polític, és necessari posar les paraules en crisis. Des del personatge de la Loca, es pensa l'homosexualitat des d'una diferència que no cap en els discursos que el llenguatge de la dictadura ha llegat a la democràcia, i així es desmantella a poc a poc el discurs d'unitat i optimisme d'aquests anys.

Paraules clau || Lemebel | Sarduy | Neobarroc | Llenguatge | Diferència | Transició 


\section{Introducción}

La década de los noventa en Chile fue la de la Transición. Saliendo de una dictadura de 17 años, el país se vio renacer en un horizonte de optimismo y alegría que prometía para el futuro una sociedad que nunca más aceptaría las atrocidades que en él se habían cometido. Nunca más desaparecidos. Nunca más presos políticos. Nunca más torturados. Nunca más dictadura ni autoritarismos. El discurso de unión y fraternidad se fraguaba tanto en los medios de comunicación como en los espacios políticos, para teñir todo de una esperanza que, más que traer justicia real, parecía maquillar de forma disimulada un aire de olvido y una idea subyacente que proclamaba «dar vuelta la página». En este contexto emerge en Chile una voz única, que desvela los cimientos sobre los que realmente se estableció el retorno a la democracia. Una voz que nace desde una diferencia, desde una no-identificación con los discursos que predominan esa transición. Es la de Pedro Lemebel: escritor, activista político, irreverente y provocativo de oficio. Las performances realizadas con su amigo Francisco Casas, bajo el nombre de «Las Yeguas del Apocalipsis», impactaron al país cuando este aún seguía bajo el mandato del tirano. En ellas, sus cuerpos eran el material artístico con el que irrumpían en eventos culturales, políticos, y desconcertaban a un Santiago que aún no despertaba completamente de su letargo. En cuanto a su obra literaria, casi totalmente en prosa, fue una de las que marcó de forma definitiva una línea que ponía en jaque la democracia naciente en el país, que pretendía mostrarse como ejemplo para el mundo. En el género que le resulta más prolífico, la crónica, juega a resquebrajar lentamente ese discurso de paz y armonía, para mostrar que aquello que se creía muerto y enterrado aún late, no solo en las leyes presentes, o en las mismas figuras públicas que se repiten sin tener vergüenza de su pasado, sino también en las palabras que el país todavía habla. Ahora bien, es el año 2001, más de una década después del fin de la dictadura, cuando aparece uno de sus textos fundamentales y que terminaría por ser su única novela: Tengo miedo torero.

En esta novela se presentan dos relaciones amorosas en el contexto histórico del fallido atentado al dictador Augusto Pinochet el año 86. Una es la de este último con su esposa Lucía Hiriart. La otra es la de Carlos, miembro del Frente Patriótico Manuel Rodríguez ${ }^{1}$, con la Loca del frente, figura que comienza a desarticular poco a poco el mundo y discurso del resto de los personajes. Ahora bien, más allá de la casa y las calles de la ciudad, de los símbolos presentes en el relato, de los distintos personajes que aparecen a lo largo de la narración, ocurre lo que es reiterativo en prácticamente toda la obra del escritor: «aquí, el protagonista es el lenguaje. Gozo del lenguaje y lenguaje del gozo: los sonidos, la acústica, la música de las palabras, las sinestesias; sinónimos y redundancias; deformaciones e invento de vocablos» (Bianchi, 2015: 330). Más allá de sus espacios, de sus manteles, de sus locas, de sus dictadores, si hay algo que marca la obra y permite plantearla desde una diferencia es el lenguaje que Lemebel utiliza al momento de narrar y también de dar voz a los personajes. En este punto, resulta importante el concepto de barroco, con todo lo que este implica tanto a nivel de estilo como también histórico. Es la línea en que la mayoría de la crítica sitúa a Lemebel: un barroco latinoamericano, definido y teorizado por el cubano Severo Sarduy como neobarroco, y luego encarnado en Argentina por Néstor Perlongher con el nombre de «neobarroso». En este linaje, se ha visto el estilo del autor chileno «como un "neo-barrocho", por un barroco que llegando a Chile pierde el fulgor isleño y la majestuosidad del estuario trasandino, al empaparse y ensuciarse con las aguas mugrientas del río Mapocho» (Bianchi, 2015: 324). Así, el autor se adscribe a una literatura en la cual el tratamiento de la lengua adquiere un papel fundamental, pero se aleja de las perspectivas elitistas que el barroco en sus 
orígenes podría adoptar, sumando la historia que otros escritores latinoamericanos le otorgaron: «Entre el pasado estático de las ficciones políticas y un futuro que las aniquile, está la poesía que decidió convertirse en barro, es decir, en la sustancia baja y elemental que desdibuja la perla y enjoya el detritus» (Panesi, 1996: 45). Se entra, de esta forma, en una obra que se otorga el derecho a plantear temáticas vistas históricamente como sucias e incompatibles con lo literario, y hacerlo desde un uso político del lenguaje, el cual comprende que, para comenzar a estructurar una sociedad diferente, no puede hablarse una lengua amaestrada.

Es necesario mencionar que esta propuesta de lectura no es nueva ni original. Mucho se ha escrito sobre la relación de Lemebel con el neobarroco y cómo ésta puede adquirir un carácter subversivo. Como señala Pérez, «la mayoría de los artículos confluyen en observar en Tengo miedo torero una subversiva y reivindicadora respuesta al contexto sociopolítico del personaje» (2019: 304). El objetivo de este artículo es, entonces, humilde: no pretende sentar nuevas bases de pensamiento sobre el autor, pero sí poder aportar algo a ese diálogo ya existente a través de una lectura exhaustiva que piense y descifre cómo el tratamiento de la lengua que existe en su obra configura la base de una crítica al proceso de transición vivido en Chile. Por ello, como ya se ha señalado, el protagonista de este trabajo será el lenguaje y sus formalidades. Para esto, resulta importante comprender la línea en la cual se enmarca su obra, es decir, el desarrollo del barroco en Latinoamérica, por lo que se realizará, en primer lugar, un análisis retórico de la novela Tengo miedo torero según las propuestas teóricas que propone Sarduy para el neobarroco. Esto no constituye un fin en sí mismo, sino que es el primer paso para comprender los recursos utilizados por el novelista, y así avanzar hacia la segunda parte del trabajo, que es explicar cómo la lengua, vista por muchos como mera herramienta de comunicación, en Lemebel se transforma en un arma de lucha política: una que pueda, por un lado, entregar una visión propia y diferente de lo que ha sucedido en el Chile postdictatorial y, por otro, romper los paradigmas bajo los cuales se ha estructurado la sociedad de ese país.

\section{El barroco y el neobarroco}

El barroco ha sido definido, en gran parte, como una contraposición a lo que sería el arte clasicista. Contra la idea del orden, armonía y aparente claridad de la obra, aparece el barroco a fines del siglo XVI como una forma de saturación de espacios, en la cual el principio de economía del lenguaje es intercambiado por el de la abundancia, el de claridad por el de oscuridad. Emerge en la obra artística el desorden, la desviación que dificulta la lectura, donde la metáfora adquiere un papel fundamental, ya que es el mecanismo con el cual comienza a desequilibrarse el universo aparentemente rígido de la palabra. Así, el espacio barroco es el de la «superabundancia y el desperdicio. Contrariamente al lenguaje comunicativo, económico, austero, reducido a su funcionalidad servir de vehículo a una información-, el lenguaje barroco se complace en el suplemento, en la demasía» (Sarduy, 1974: 100). El eco de esta literatura a través de los siglos parece dormirse y despertar en diferentes partes del mundo. Es olvidada y despreciada, y luego aparecen nuevos lectores que ven en sus premisas una forma de expresión diferente y audaz, que permitiría entender de forma paulatina la obra como un juego, en oposición a la obra clásica en cuanto trabajo. Así llega el siglo XX en Latinoamérica, y comienzan a realizarse diferentes lecturas del fenómeno de lo barroco.

Dentro de estas lecturas, existe una tesis esencialista (a la que se adscribe, por ejemplo, Carpentier) que proclama lo barroco como una tendencia que es 
permanente en la humanidad: «Esta esencia universal, regida por el ritmo cíclico de un eterno retorno, estaría presente desde la noche de los tiempos y contaría con innumerables manifestaciones en todas las edades y todas las geografías» (Guerrero, 1987: 14). Esta idea permite definir espíritus humanos como plenamente barrocos, y llevarlo incluso más allá: proclamar a América Latina como un continente barroco, tanto por la vida natural expresada en su flora y fauna, como también por las personalidades desarrolladas en este continente. Esto conlleva una problemática: parece existir un abuso del adjetivo, denominando así a cualquier expresión o corriente que se oponga a lo clásico o a lo ordenado. Este es justamente el problema que constata Sarduy. El cubano viaja a París en 1960 para cursar sus estudios. En esta estancia (que termina siendo indefinida) desarrolla, desde lecturas que realiza de Lezama Lima, la propuesta del neobarroco. Así proclama una idea que se contrapone a la tesis esencialista, y que después expresa así Deleuze: «El Barroco no remite a una esencia, sino más bien a una función operatoria, a un rasgo. No cesa de hacer pliegues [...] los lleva hasta el infinito, pliegue sobre pliegue, pliegue según pliegue» (1989: 11). A diferencia de la propuesta esencialista, se entiende lo barroco no cómo una visión de mundo permanente que se expresa en palabras, sino como el uso de determinadas técnicas que harían nacer una cosmovisión diferente. Se invierte el modelo de la causa y la consecuencia: es la diferencia marcada en el lenguaje la que permite que emerja un verdadero quiebre en la tradición de lo clásico.

El trabajo de Sarduy es proponer lo que sería el neobarroco y «reducirlo a un esquema operatorio preciso, que no dejara intersticios, que no permitiera el abuso o el desenfado terminológico de que esta noción ha sufrido recientemente» (1977: 168). Estas operaciones nacen desde la idea de artificialidad del primer barroco, de un proceso de enmascarar la palabra que el autor cubano encuentra en Góngora: su misma propuesta de la metáfora es «metalingüística, es decir, eleva al cuadrado un nivel ya elaborado del lenguaje, el de las metáforas poéticas» (1977: 169). El llevar al extremo la idea de la lengua como un artificio con el cual se puede crear sobre la marcha aparece en gran parte de la novela de Lemebel. Un breve ejemplo es cuando nombra al miembro masculino como un «dedo sin uña que pedía a gritos una boca que lo anillara» (2001: 99). En este fragmento, sobre una metáfora inicial («dedo sin uña») se sigue trabajando para, así, dar paso a la idea de una felación utilizando la boca como anillo, como si el concepto de dedo estuviera en su carácter denotativo. Así, sobre la metáfora del dedo se sigue jugando y desarrollando esa idea del lenguaje como artificio. Más allá de esto, Sarduy reconoce, como se dijo, algunos procedimientos específicos característicos del neobarroco que también se pueden encontrar de forma constante en la escritura de Lemebel.

\subsection{Sustitución}

Un primer recurso es el de la sustitución. Sarduy explica que en éste «el significante que corresponde al significado [...] ha sido escamoteado y sustituido por otro, totalmente alejado semánticamente de él y que solo en el contexto [...] del relato funciona» (1977: 169). Esto implica un quiebre en la idea tradicional del lenguaje como herramienta comunicativa, ya que abre una especie de falla entre lo nombrado y lo nombrante. El significante que se asocia a un determinado significado se cambia por otro que no mantiene la relación semántica, y que presenta usualmente una distancia exagerada. En el caso de Tengo miedo torero, hay variados ejemplos de este tipo de operaciones. El tratar de "charqui ahogado en collares» (Lemebel, 2001: 99) a una señora de edad, «condón para dinosaurio» (2001: 21) a un paquete que Carlos había 
dejado en el hogar de la Loca, o bien «luna añeja» (2001: 84) al rostro protagónico de la novela son solo algunas muestras de la operación neobarroca. Uno de los elementos que se presenta a través de más y variadas metáforas es el miembro masculino, mostrado ya en el apartado anterior como «dedo sin uña» (que mantiene aún cierta cercanía semántica con el original). Cabe mencionar en este punto un ejemplo que muestra de manera clara cómo el proceso de sustitución funciona en la novela: «Y ahí estaba... por fin, a solo unos centímetros de su nariz ese bebé en pañales rezumando a detergente» (2001: 99). Esta escena se sitúa cuando la Loca del frente estaba pronta a realizarle sexo oral a un Carlos que se encontraba inconsciente por la borrachera. En ese punto, había desabrochado recientemente sus pantalones, y solo teniendo en cuenta ese contexto anterior se puede apuntar que «bebé en pañales» hacía referencia al miembro masculino de Carlos aún cubierto por su ropa interior. La metáfora funciona a pesar de la distancia semántica establecida entre ambos significantes y su significado tradicional.

\subsection{Proliferación}

Sobre este procedimiento, Sarduy señala que consiste en ocultar el significante de un significado, «pero no remplazándolo por otro, por distante que éste se encuentre del primero, sino por una cadena de significantes que progresa metonímicamente y que termina circunscribiendo al significante ausente» (1977: 170). Se comienza a articular en este punto una de las principales características del neobarroco: su carácter contraeconómico. Aquello que puede expresarse a través de un significante se expresa en palabras que se van derrochando una tras otra, y, así, se llena el espacio y se hace que la comunicación, que debería ser concisa y precisa, se estire, se alargue y pueda comenzar a difuminarse por su propia abundancia. En Tengo miedo torero, se estructura el significante «soledad» de la Loca a través de una cadena de otros significantes que aluden hacia él: "Y después un calzoncillo tieso, un calcetín olvidado, una botella vacía sin mensaje, ni isla, ni tesoro, ni mapa donde enrielar su corazón golondrino» (Lemebel, 2001: 16). La sumatoria de prendas de vestir que parecen abandonadas, y luego la figura de una botella que carece de lugar o utilidad dentro del mundo son las que remiten a la palabra omitida, a la soledad. De la misma forma, en el comienzo de la novela, se utiliza una proliferación de significantes diferentes: "fuego de neumáticos», "patrullaje», "caceroleo», "apagón», "chispazo eléctrico», "oscuridad completa», "camión blindado», "el párate ahí mierda», "disparos», "castañuelas de metal», «noches fúnebres», "gritos» (2001: 9). Estos expresarían los dos significantes (dictadura y protestas) centrales que situarían el escenario histórico donde se desarrolla la novela: un régimen autoritario, pero con algunas manifestaciones que comienzan a aflorar dentro de ese contexto.

Así, se va ejecutando en la novela la lógica contraeconómica de «Malgastar, dilapidar, derrochar lenguaje únicamente en función de placer $-\mathrm{y}$ no, como en el uso doméstico, en función de información» (Sarduy, 1974: 99). Resulta pertinente mostrar también acá otras alusiones que se realizan al miembro masculino a través del recurso de la proliferación. En una escena cuando la Loca está sintiendo, en un bus del transporte público, a un hombre fregarse contra su cuerpo, se narra sin decir directamente la palabra. Es evitada su expresión directa, y se le menciona como «animal», "fofo reptil», «enjaulado resorte» y «pitón» (Lemebel, 2001: 77). Puede verse acá que hay una línea en la cual se mueve el autor para realizar su proliferación que puede, por segundos, desdibujar el significado original. Ahora bien, en la propuesta de Sarduy, se explica que algunas veces «la agrupación heterogénea de objetos "vaciados" no nos conduce, ni aun de manera sutilmente alegórica, a ningún 
significado preciso» (1977: 171). Lemebel no parece llegar a este extremo. Ahí donde está cerca de perder el control de la metaforización, parece utilizar un freno y no llegar a una proliferación de significantes que se descontrole por completo, que sería característico de cierta obra neobarroca. Acá no hay un vaciado total de las palabras, solo un distanciamiento provisorio, una lejanía potente, pero que permite al lector volver sobre cierto significado. Así, los recursos neobarrocos no derivan en una literatura que resulte en exceso compleja.

\subsection{Condensación}

Este tercer punto muestra de forma potente la idea del juego a través del uso del lenguaje. En este existe una «permutación, espejeo, fusión, intercambio entre los elementos - fonéticos, plásticos, etc.- de dos de los términos de una cadena significante, choque y condensación de los que surge un tercer término» (Sarduy, 1977: 173). Es decir, hay una unión de dos significantes que apuntarían a un significado que será un resumen de aquellos a los que aluden ${ }^{2}$. En el caso de Tengo miedo torero aparecen muchas expresiones que realizan la condensación como procedimiento: «marifrunci» (Lemebel, 2001: 16), «coliflor» (22), «locamater» (39), «colijunta» (45), «marichusca» (53), «marilaucha» (63), «maricoipa», (85), «maricueca» (90), «colifrunci» (112), solo por nombrar algunos ejemplos. Se puede apreciar que gran parte de las expresiones nacen de un primer significante que apelaría a «maricón» o "marica» (o "cola», otra forma chilena de referirse al homosexual), al cual se le van agregando diferentes connotaciones a través de otros significantes. Estos producen que el término inicial se vaya doblegando sobre sí mismo en distintas formas, entregando así la idea de una diferencia que no puede definirse a través de una sola conceptualización, sino que permite inserciones "prolongable[s] al infinito» (Sarduy, 1977: 173). Se entrega la idea de un texto vivo a través del cual se puede seguir el juego de aquellas palabras que empiezan a desbordarse a sí mismas a través de, utilizando la misma palabra que se instala en la novela, una "voz mariflauta» (Lemebel, 2001: 148), que hace surgir un nuevo sentido en ese mismo juego.

\subsection{Parodia}

Señala Sarduy que «solo en la medida en que una obra del barroco latinoamericano sea la desfiguración de una obra anterior que haya que leer en filigrana para gustar totalmente de ella, ésta pertenecerá a un género mayor» (1977: 175). Esta idea, que abraza la tradición quijotesca, permite un espacio que continúa la idea de deformación de aquel texto anterior, a través de procedimientos que pueden ridiculizarlo, exagerarlo, e incluir en él nuevas voces discordantes con su realidad inicial. En Tengo miedo torero aparecen algunas obras que sientan un referente con el cual esta novela claramente dialoga. La más evidente (dejando de lado novelas como El lugar sin límites de José Donoso) sería El beso de la mujer araña de Manuel Puig. Al respecto, el chileno menciona en una entrevista del año 2001 que esta obra «fue un eco, digamos, sentimental que cruzaba a la izquierda con la homosexualidad, que a mí me dio el impulso para escribir con esta novela [Tengo miedo torero]» (Lemebel, 2018). Sin embargo, no hay un afán por deformar o desfigurar este texto para formar esa lectura en filigrana de la que habla Sarduy. En la entrevista citada, Lemebel continúa diciendo que la novela del argentino constituye un eco importante, pero «aparte del atentado, el atentado es el telón de fondo que enmarca esta relación» (2018). Pareciera que la base de la novela es la misma realidad histórica vivida en el país. Ella es la que se parodia de 
forma constante, a través tanto de expresiones de los personajes o de sus mismas vivencias. Ejemplo de esto son las constantes referencias a momentos históricos vistos desde una perspectiva nueva. En el atentado que sufre Pinochet, que intenta mostrarse siempre como una figura viril e incorruptible, apenas empiezan la balas, se ve que el dictador «tenía la nariz pegada al piso, temblando, tartamudeando: Ma-mama-cita-linda esta güevá es cierta. Y tan cierta que el pavor de los escoltas no los dejaba reaccionar. Y pálidos se escondían como ratas en el fulgor de la balacera» (Lemebel, 2001: 154). Aquel ejército que tantas veces se jactó de su valentía es remarcado en este fragmento por su cobardía, y el general se esconde exclamando palabras poco esperadas en sus labios.

Ahora bien, probablemente la mayor parodia del libro encuentra su referente textual a deformar dentro de sí mismo. Este sería la relación existente y evidentemente desvirtuada que hay entre las dos parejas principales. Mientras se presenta una Lucía que habla demasiado (sobre esta idea se volverá más adelante) y un marido callado que no la soporta, se muestra una Loca que inventa y reescribe de forma libre y plural, sumado a un personaje masculino que en este caso cede (o parece ceder) su virilidad ante lo que ella le provoca. La pareja del dictador con su esposa resulta terriblemente frívola, desarrollando un espacio en que realmente no se escuchan y parece ser una relación cerrada sobre sí misma, que no tiene la opción de agregar nuevos registros ni crecimientos dentro de su historia. La pareja de la Loca y Carlos es todo lo contrario: logra abrir espacios a través, principalmente, del lenguaje utilizado por ella, y un hombre que mantiene cierta permeabilidad en su perspectiva vital, que es capaz de ser transformado (o, quizás, liberado).

Un ejemplo concreto de lo anterior remite a la escena del cumpleaños de Carlos que es celebrado por la Loca, como ella misma dice, "a la cubana». Invita a todos los niños del barrio y así se abre un espacio lleno de vida, abierto al juego y al desorden, lo que se traspasa a los adultos:

Carlos de qué te ríes tú grandote dando el ejemplo chorreado entero. No me abraces con las manos con merengue, no me hagas cosquillas bruto que no aguanto, que me resbalo, que me caigo, Carlos, sujétame. Y los dos cayeron juntos en medio de la chuchoca pinganilla que alborotaba la fiesta de los pitufos, rojos de tanta risa, de tanta torta y golosinas que comieron hasta hartarse (Lemebel, 2001: 92).

En su contraparte absoluta está el cumpleaños que se celebra del dictador, descrito por la repetición de los mismos procesos que vienen hace años, y una mujer que, al parecer, como el mismo Pinochet dice, «ni siquiera el día de su cumpleaños se podía callar» (2001: 105). En este punto él recuerda un cumpleaños infantil marcado por un ambiente de orden y silencio donde, además, sus invitados no llegaron. Siendo tarde, el timbre se había mantenido en silencio, «y Augustito estaba mudo cuando entró su madre, que secándose la mirada vidriosa, quiso hacerlo todo nada, alternando la voz con una risita optimista, llamando a la empleada para que prendiera las velas» (2001: 108). De esta forma, este espacio apagado y solitario de los poderosos contrasta con el relato lleno de vida y colores en los que goza la pareja de la Loca y Carlos. Lo que vendría a ser la misma idea de familia, de matrimonio y de amor (que han sido definidos, principalmente, desde el conservadurismo) aparece triste con relación a aquella alegría vivida por quien no se enmarca dentro del sistema social operante.

En ese espacio paródico que se abre al juego aparecen nuevos registros y voces que son impensables en la relación de Lucía y Pinochet. En la relación de la Loca y Carlos se muestra el neobarroco que se compromete y que 
«genera la deformación sistemática de sus antecedentes literarios y/o culturales con el objetivo de movilizar la parodia y desactivar consecuentemente los discursos cristalizados en ellos» (Cid, 2017: 53). Así, por ejemplo, se introducen diferentes registros sociales que permiten desarticular esa perspectiva cerrada del sujeto, que se presenta en el tirano y su mujer. En la prosa de Lemebel, se permiten dentro del mismo espacio expresiones de corte bastante popular, explícito y asociado a las clases bajas, por ejemplo, cuando señala «esas tontas no saben lo que es un hombre, nunca han tenido un macho con olor a huevas y sobaco que les dé vuelta el hoyo a cachas» (2001: 114). Estas aparecen junto a otras que sugieren un uso del lenguaje bastante cercano al registro culto asociado a ciertas clases altas: «trepó la escalera del altillo alcanzando una vista encumbrada de la ciudad mohosa en el aluminio óxido de los techos» (2001: 115-116). Se forma así un espacio «del dialoguismo, de la polifonía, de la carnavalización, de la parodia y de la intertextualidad» (Sarduy, 1977: 175) donde lo barroco aparece como una red de diferentes registros, saliéndose de la planicie del lenguaje representacional para ingresar en el dinamismo del juego.

Dentro de la idea de la parodia toma fuerza el concepto de intertextualidad, que Sarduy entiende como la «incorporación de un texto extranjero al texto, su collage o superposición a la superficie del mismo, forma elemental del diálogo, sin que por ello ninguno de sus elementos se modifique, sin que su voz se altere: la cita» (1977: 177). Sin embargo, se mantiene el sentido paródico, por lo que la cita, ese texto que se inserta dentro del otro, se resignifica de acuerdo con el contexto particular en el que se lo enmarca. Se deforman, se vacían de su sentido original y son empleadas con fines tergiversados, que traicionan al código al que pertenecen. El ejemplo más evidente dentro de la novela es el uso de canciones. Hay dos en las que vale la pena detenerse: la que le entrega el título a la novela, y la que le otorga su final. Esta última es llamada «Mantelito blanco», cuyo motivo ya se encuentra presente en todo el libro debido a la recurrencia de aquella figura, en este caso bordada de ángeles y pájaros. Esta canción, compuesta por Nicanor Molinare, se asocia a las agrupaciones cercanas al sector más conservador del país. Por esto, cuando Lemebel cierra su novela con una cita que canta "Tienen sus dibujos / figuras pequeñas / avecitas locas / que quieren volar...» (2001: 194), transforma una tradición ligada históricamente a lo militar y a sectores católicos, apropiándose de esas "avecitas locas" desde la representación del homosexual como pájaro. Así, aquellas palabras que estuvieron en la boca de la derecha chilena se subvierten, abriéndolas a nuevas posibilidades. Algo similar pasa con la canción "Tengo miedo torero», que le entrega el nombre a la novela. Si bien aparece a lo largo de gran parte del texto, la cita se presenta de esta forma: «iTengo miedo torero / tengo miedo que en la tarde / tu risa flote!» (2001: 93). Al ir a la canción original, se puede notar que lo que se presenta como una cita exacta acá tiene una pequeña modificación. Transforma el «temido grito» en «risa», cambiando la idea de lo arriesgado por el goce y el juego. Esto resulta representativo, ya que mientras la figura del torero se asocia a la masculinidad y la virilidad, en la novela se utiliza como código de una relación homosexual. Hay un juego constante en la novela de transmutar la idea de género con sus representaciones y conceptualizaciones tradicionales.

\subsection{Erotismo}

Sobre el erotismo, más que un mecanismo particular, Sarduy señala una característica que parece atravesar toda la obra: «Juego, pérdida, desperdicio y placer: es decir, erotismo en tanto que actividad puramente lúdica, que parodia de la función de la reproducción, transgresión de lo útil, del diálogo 
"natural" de los cuerpos» (1974: 101). De esta forma, la idea de lo lúdico se muestra en un lenguaje que parece, poco a poco, olvidar su papel utilitario para pasar a desarrollar una actividad netamente placentera: el «lenguaje se ha vuelto no vehículo de algo, llámese significación, significado, o sentido, sino un montaje de cuerpos amados y odiados, de brazos, de piernas, de torsos, de manos y pies, de cabezas y senos» (Rosa, 2006: 128). Esa idea de lengua como producto que se puede armar y desarmar para el propio goce del sujeto, más allá de lo comunicativo, se muestra en el cierre de la conversación de la Loca con la que llama su mamá Rana: "Seguro Carlos, porque mi mami después se pone cargante. Venga el burro... ${ }^{3}$, repicó la Rana. Por detrás y por delante, dijo la otra. Ay niña, no hay quien lo aguante, siguió la Rana. Para usted mi comandante, terminó payando la Loca del Frente» (Lemebel, 2001: 134). Aquí no prima lo denotativo o lo directo, sino que plenamente el juego, una conversación inútil en cuanto a lo comunicado, pero que se vuelve relevante en cuanto a la capacidad de gozo que otorga.

\section{Nuevo lenguaje, nueva sociedad}

Como ya se planteó, los recursos utilizados por Lemebel tienen un afán que es político. Se transforma el lenguaje para transformar la realidad. Sin embargo, ¿por qué una transformación de la lengua puede traer cambios sociales?, ¿qué valor subversivo presenta un cambio en las palabras? Se vuelve necesario exponer breve y esquemáticamente algunos aspectos sobre el lenguaje: su importancia en la concepción de la realidad de cada sujeto, y también el rol de poder que ejerce sobre la conciencia ( $y$ también la subconsciencia). Para esto hay que dirigirse principalmente hacia la tradición alemana, donde el pensamiento sobre el lenguaje mismo comienza a adquirir, desde fines del siglo $\mathrm{XVIII}$, una importancia que crece de forma sistemática hasta llegar al XX, cuya filosofía está empapada de esta problemática. Se empieza a comprender que una transformación radical del pensamiento debe pasar necesariamente por un proceso de crisis del lenguaje. No en vano, uno de los pensadores decimonónicos más rupturistas, como Nietzsche, señala «no nos libraremos de Dios en tanto sigamos creyendo en la gramática» (2019: 52).

Una de las principales ideas que entrega Nietzsche es que, al contrario de lo que se ha creído desde la tradición griega, «el lenguaje no es una episteme, es decir, no nos dice lo que son las cosas en su esencia y verdad» (de Santiago, 2000: 23). No hay un mundo preexistente que el lenguaje pueda describir de forma objetiva, ya que el mismo hecho de nombrar ese mundo constituye un proceso de conceptualización que encierra las posibilidades de la realidad en una esfera de palabras que imponen un límite a la mente del sujeto: no se puede pensar fuera de este lenguaje. Así entonces, cualquier conclusión a la que se llegue a través de la lengua es solo una opinión, una ilusión que no es conocimiento real. Dicho de otra forma, cualquier «expresión no es más que un símbolo» (Nietzsche, 2000: 114). El problema reside en que ese cielo conceptual en el cual el hombre se mueve, construido por metáforas iniciales, es tomado como una forma de expresarse que puede nombrar de forma objetiva el mundo. Así, quien domina el lenguaje maneja la realidad y las posibilidades del sujeto, pero este proceso, que es totalmente ideológico, es tomado por natural, ya que el hombre «olvida que las metáforas intuitivas originales no son más que metáforas y las toma por las cosas mismas» (Nietzsche, 2001: 29).

De esta forma, aquella palabra «que parecía ser tanto, incluso todo, [...] está propiamente vacía, especialmente vacía de sentido» (Nietzsche, 1998: 53). Esto conlleva que cuestionar ese mismo lenguaje, poner en crisis la relación 
entre la palabra y el objeto, implica también borrar las marcas autoritarias de verdad y poder que empiezan a nacer en las distintas interacciones. La práctica del neobarroco no es un inocente juego con el lenguaje, sino que «refleja estructuralmente la inarmonía, la ruptura de la homogeneidad, del logos en tanto que absoluto, la carencia que constituye nuestro fundamento epistémico» (Sarduy, 1977: 182). Así, todos los recursos utilizados por Lemebel en su práctica escritural reflejan lo mismo: un cuestionamiento del lenguaje en que se formaron lo acuerdos y también las diferentes subjetividades presentes en el país. Aquellas palabras que dicen ser dueñas de la verdad no son más que eso: palabras, conceptos fosilizados cuyo mismo valor retórico ha sido olvidado, y se han impuesto como si fueran las cosas mismas. Finalmente, «el lenguaje, [...] lo mismo que la retórica, tiene una relación mínima con lo verdadero, con la esencia de las cosas» (Nietzsche, 2000: 91), por lo que cuestionar esa palabra «verdadera» debe ser el primer paso para poder poner en crisis las estructuras sociales en las que se sustenta un país. La metáfora, entonces, adquiere un valor fundamental, ya que es la que puede mostrar ese carácter inestable del lenguaje: «la metáfora es un lenguaje naciendo, un lenguaje que está siendo, pero que todavía no es, en definitiva, la mejor forma de expresar que el lenguaje es devenir y que solo vive en el movimiento de la metáfora» (de Santiago, 2000: 47).

Además, este lenguaje cuyo valor metafórico inicial se olvida, juega un rol preponderante en la articulación de cada sujeto: «El hombre no existe antes que el lenguaje, ni como especie ni como individuo. Nunca encontramos un estado en el que el hombre esté separado del lenguaje» (Barthes, 1970: 154). Por lo tanto, para hacer nacer nuevas subjetividades, es menester cuestionarse la propia lengua ${ }^{4}$, aquel cielo conceptual en el que se mueve cada sujeto y que, inherentemente, elimina las diferencias. "Todo concepto se forma por equiparación de casos no iguales» (Nietzsche, 2001: 23), por lo que la conceptualización se encarga de pulir lo diferente, aquello que escapa a la norma que ese mismo lenguaje impuso como verdad. Así, cuando la Loca se expresa de forma diferente, cuando se dedica a derrochar palabras que cuestionan la relación que estas tienen con la esencia de las cosas, está reivindicando aquello que en ella es diferente. Aquello que no cabe en la lengua ni de Pinochet, ni de Lucía Hiriart, ni tampoco de Carlos. Así, el neobarroco de Lemebel «se trata de una práctica estética que pasa por el cuestionamiento de las identidades, tanto a nivel nacional como individual» (Wasem, 2010: 226), logrando poco a poco, a través de la diferencia que marca desde la palabra misma, revolucionar la mente de quienes lo rodean.

\subsection{La voz mariflauta contra Lucía y el dictador}

Lo anterior se representa en la diversidad de usos del lenguaje a los que se contrapone la voz de la Loca. En primer lugar, existe un fuerte contraste entre la forma en que ella se relaciona con el mundo a través de la lengua y cómo lo hace la otra pareja protagónica. En la dinámica de esta relación, ella habla muchísimo mientras él, usualmente, está en silencio. Es interesante, a modo de ejemplo, mostrar lo que Pinochet piensa del constante parloteo de su mujer: "Semana a semana las mismas discusiones le llenaban la cabeza. Que Gonzalo me dijo, que Gonzalo dice, que Gonzalo cree, que debieras tomar en cuenta la opinión de Gonza, que es tan fino y tiene tan buen gusto» (Lemebel, 2001: 29). Llama la atención, más allá de la capacidad de parlotear, de pasar de un tema a otro sin la opción de cuestionar su propio hablar, la idea de repetición: el «dijo que». Esto se puede ver en muchísimas interacciones que mantiene Lucía: «Gonza dice que el color amarillo hace furor en Europa, fue el color de la temporada primavera verano» (2001: 29). Es un lenguaje que no 
cuestiona bajo ninguna circunstancia su valor de verdad, su valor de comunicación real que se puede establecer. Quiere llenar espacios, que se hable lo más posible. En este punto resulta interesante el concepto de "habladuría» que trabaja Heidegger: «Más que comprender al ente del que se habla, se presta oídos solo a lo hablado en cuanto tal. Él es comprendido; el sobre-qué tan solo a medias, superficialmente; se apunta a lo mismo, porque todos comprenden lo dicho moviéndose en la misma medianía» (2009: 187). El lenguaje parece adoptar un carácter de ruido cuya función, más que una comunicación cuyas palabras tengan un sentido profundo y meditado, es la de que se coarte la posibilidad de cuestionamiento: «la habladuría, en la que se presume haber alcanzado la comprensión de aquello que se habla, cohíbe, en virtud de esta presunción misma, toda nueva interrogación y discusión» (2009: 188). Así, el lenguaje reafirma todo lo que su carácter tiene de autoritario. Esto se refleja de forma clara en la relación que Lucía mantiene con la prensa tras el atentado:

Fue un milagro de la Virgen lo que salvó a mi marido [...] ¿Cómo qué Virgen? Usted es tonta, la Virgen del Carmen pues, la Patrona del Ejército. ¿Qué otra Virgen podría ser? No se fija que se ve clarita la imagen con el niño en brazos aquí en la ventana del auto. ¿O usted es ciega? (Lemebel, 2001: 169).

No se acepta una discusión sobre lo dicho, ya que se presume un total conocimiento de aquello que se habla: quien detenta la posibilidad de hablar, entonces, detenta el poder por sobre los demás.

En el caso del Dictador, si bien habla menos que Lucía, su voz adquiere un carácter similar cuando lo hace: "Yo odio la poesía, como le dije a ese periodista güevón que me preguntó si leía a Neruda. ¿Escribió alguna vez un poema?, me dijo el imbécil. ¿Quiere que le diga una cosa? Odio las poesías» (Lemebel, 2001: 125). Esta afirmación, más allá del carácter con que se enuncia, presenta otro tema, que es la idea del desprecio a la poesía. Esto resulta una estrategia para quienes apelan al orden tradicional: «rechazar la metáfora en aras de la buscada estabilidad y del orden conceptualizado, porque de esa forma queda excluido lo otro de la razón, el error, la mentira» (de Santiago, 2000: 49). En la poesía lo que existe es, justamente, una duda de esa idea de lenguaje como realidad y esencia de las cosas. Por esto, para el dictador se vuelve peligrosa: permitiría cuestionar una voz que él pretende incuestionable. Es mejor repetir, expresar lo que ya se ha dicho y que se ha expresado en forma de habladuría, evitando así una posibilidad de subversión de las conciencias.

Como contraparte a esta forma de relacionarse con la lengua aparece la Loca. Como se vio en el primer apartado, su lenguaje es esencialmente metafórico, lo que implica la idea de la no repetición: «la metáfora es algo "individual", sin que pueda haber otra igual, lo cual le permite librarse de toda clasificación y escapar a cualquier tipo de codificación o reglas semánticas» (de Santiago, 2000: 47). Esto se opone a la idea de lo repetido y lo incuestionable en la que se sostiene el lenguaje del dictador y su esposa. Ante lo repetido aparece lo irrepetible: «¿Y usted derramaría alguna lágrima por mí, princesa? Una sola, nada más que una, pequeñita, pequeñita, como una perla amarga que se quedó sin mar. ¿Nunca has pensado escribir?, tú hablas en poesía. ¿Lo sabes?» (Lemebel, 2001: 130). Esta expresión de Carlos es lo que sostiene a la Loca como personaje. Habla a través de metáforas, de aquellas que ella va creando y produciendo, lo que le permite escaparse de las definiciones y conceptualizaciones que la sociedad impone a los sujetos a través del lenguaje. Quizás no permitirle, quizás no lograrlo efectivamente, pero sí salir de la repetición. El no repetir, el utilizar un lenguaje que se marque desde su 
diferencia, es también una posibilidad de rearticularse a sí mismo en un mundo que se cierra.

\subsection{La voz mariflauta contra el hombre}

Otra voz a la que se contrapone la de la Loca es a la del mismo Carlos. Para ejemplificarlo, en la obra cada uno narra una vivencia sexual de su niñez. En el caso de Carlos, relata cómo, con un compañero, se masturbaron frente a frente, queriendo penetrarse. Esto es relatado como si fuera una tontería sin importancia, pero el lenguaje utilizado es en extremo directo: «Y ahí estábamos los dos frente a frente con el picazo duro y colorado entre las manos [...] tú primero, me contestaba él pajeándose, acercándome su pichula descuerada» (Lemebel, 2001: 96). Ya se expuso que, en la novela, prácticamente todas las alusiones al miembro masculino se realizaban a través de metáforas. Sin embargo, acá Carlos utiliza dos significantes que en Chile refieren directamente al pene masculino: «picazo» y "pichula» ${ }^{5}$. Es un lenguaje que no se cuestiona a sí mismo, y la misma Loca se ve descolocada no por la historia, sino por «la forma de contar que tienen los hombres. Esa brutalidad de narrar sexo urgente» (Lemebel, 2001: 97). De esta forma, Carlos, quien debería representar al revolucionario, sigue manejándose en una forma de relacionarse con la lengua que no escapa a la figura del macho: lo directo, lo no metafórico, lo sexual de forma urgente y apresurada. Es solo a través de la Loca que Carlos puede empezar a escaparse de estos esquemas que siguen tiñendo los relatos.

Como contraste, en el caso de la Loca, narra un caso que es mucho más duro y crudo, cuando habla de la figura de su padre en su niñez:

A él tan macho, tan canchero con las mujeres, tan encachao pa las putas, tan borracho esa vez manoseando. Tan ardiente su cuerpo de elefante encima de mí punteando, ahogándome en la penumbra de esa pieza, en el desespero de aletear como pollo empalado, como pichón sin plumas, sin cuerpo ni valor para resistir el impacto de su nervio duro enraizándome. Y luego, el mismo sinsabor del no me acuerdo, el mismo calcetín olvidado, la misma sábana goteada de pétalos rojos, el mismo ardor (Lemebel, 2001: 16-17).

Justamente acá la idea de prisa, de necesidad urgente de narrar, se difumina. En la metaforización y los recursos neobarrocos utilizados, el principio de economía se borra, y lo que se puede decir con poco se dice con mucho. Sin embargo, a diferencia de la habladuría, acá se estructura esa lengua como lo irrepetible, y cuando describe la penetración como enraizamiento, por ejemplo, escapa totalmente de la idea de lenguaje directo. La relación entre la palabra y la cosa acá se aleja, por lo que el lector tiene que realizar un paso más para la comprensión de lo dicho. A diferencia, entonces, de la narración de Carlos, acá ese paso extra es el que, a medida que continúa repitiéndose, hace cuestionar la verdadera relación entre el lenguaje y el mundo, entre la palabra y la cosa.

\section{Romper el paradigma: el Chile postdictatorial}

Pedro Lemebel, a través de su prosa neobarroca, logra mostrar que es posible la estructuración de un lenguaje diferente al reproducido por los poderes fácticos de la dictadura. Sin embargo, se ha dicho en este trabajo que la principal crítica del autor no es solo hacia este periodo en específico, sino también hacia una transición democrática que se jactaba de ser ejemplar. Es de vital importancia recordar que la novela en cuestión, Tengo miedo torero, fue publicada cuando ya la democracia había llegado hace más de una década. ¿Qué tipo de sociedad es la que se representa? ¿Qué aspectos suyos se 
pueden seguir reproduciendo, a través del lenguaje, en el Chile del siglo XXI? Cuando la Loca le señala sobre el final de la novela a Carlos « ¿Te fijas cariño que a mí también me falló el atentado?» (2001: 194) parece referirse a que, incluso en el año 2001, el dictador no ha muerto: sigue vivo a través de una sociedad que rechaza lo diferente en pos de un futuro lleno de promesas de unidad y prosperidad. A través del lenguaje, entonces, Lemebel quiere desarticular una idea de país determinada que se sostenía en un discurso presente en la dictadura y que permanecía en sus años posteriores.

Estos años, los 90, se forman entre el discurso oficial que reafirma una idea de país que avanza hacia el orden y otro discurso subterráneo, el de los restos y despojos de la memoria que formó la literatura postdictatorial. «Las historias se descomponían en vez de componerse, los triunfos, pasajeros o no, se deshilvanaban hilo por hilo hasta quedar nuevamente enredados en la madeja informe de la que habían salido» (Bottinelli, 2016: 8). Así, nació una literatura de las ausencias que quiso, de diferentes formas, desarticular el oficialismo. Sobre este punto, Nelly Richard rescata el papel del neobarroco en la literatura de transición en un análisis, principalmente, de Diamela Eltit. En este, señala que esos restos se encontraban «envueltos por una superabundancia de artificios destinada a reparar los contenidos de menos (carencias sufridas, violencias padecidas) con el lujo de formas de más: suplementarias y abigarradas, es decir, estéticamente cargadas de una diversidad proliferante y móvil de significantes» (2001: 79). Es este el gesto que adopta también Lemebel, que escribe esta novela a partir de algunos papeles sueltos, perdidos hace tiempo, que nacieron en la dictadura ${ }^{6}$. Toma esos trozos, esos retazos de historia y les otorga una voz diferente, excesiva. Un lenguaje que se subvierte contra un sistema social que se ha apropiado del micrófono y los altavoces. Este sistema es el que esas escrituras subterráneas comenzarán a atacar: los fragmentos desarticulados querrán rebelarse contra el orden.

En el libro en concreto, el entramado social chileno, el orden, se define por un paradigma que opone principalmente dos contrarios: por un lado, la derecha personalizada en el dictador y los militares; por otro, la izquierda que se materializa en el Frente Patriótico Manuel Rodríguez, o a través del constante apelativo «marxista». Esta es la estructura en la cual se pretende situar a sí misma la sociedad chilena, una donde

Todo gira imaginariamente a través de "un centro», en tanto el centro se enumera como cero del cual se empieza a contar. Es a partir de allí donde se generan las atribuciones (sexo «débil»-sexo «fuerte»), las asignaciones (femenino-masculino, macho-hembra), las fuerzas (activo-pasivo) (Rosa, 2006: 125).

Y, por supuesto, izquierda-derecha. Uno de los principales elementos para generar una conciencia colectiva de los actores sociales que se encuentran en ese centro son los medios. Lemebel lo hace a través de los anuncios de Radio Cooperativa. En estos, pueden encontrarse mensajes en los que la rebelión está asociada al grupo armado mencionado: «SE HAN INCAUTADO ARMAS DE PESADO CALIBRE Y NUMEROSO MATERIAL IMPRESO LLAMANDO A LA REBELIÓN, PERTENECIENTE AL LLAMADO FRENTE PATRIÓTICO MANUEL RODRÍGUEZ» (2001: 35). Por otro lado, la misma radio era presentada por el dictador como «esa Radio Cooperativa y su tararán marxista que tenía revolucionados a los flojos de este país. A esa patota de izquierdistas que no querían trabajar y se lo pasaban en protestas y subversiones al orden» (2001: 20). Así, la oposición se encasilla entre marxistas (que parecen alérgicos al esfuerzo) y revolucionarios armados. Al contrario de la ecuación, la derecha y los militares son representados en la voz casi omnipresente del tirano: «todas las emisoras discurseaban la misma voz del Dictador hablando por cadena 
nacional» (2001: 79). Así, Chile se vuelve un país en el que el sujeto tiene dos opciones: o es pinochetista o es marxista, o es militar o es del Frente.

¿Dónde queda la figura de la Loca en esta dicotomía? Es rechazada por la derecha. Aparece un personaje militar que, en su forma de hablar, a Pinochet le resulta amanerado: "Tiene voz de maricón este cabro, pensó el Dictador» (Lemebel, 2001: 139). La palabra militar conlleva una carga conceptual que está ligada, especialmente para los grupos conservadores, con la hombría y la virilidad. Ante la primera duda de esta hombría, llega el rechazo y la expulsión. En cuanto a la izquierda, el mismo Lemebel, comunista irrenunciable, señala la desconfianza de la que fue víctima por parte del Partido: "Usted cree que pienso con el poto / Y que al primer parrillazo de la CNI / Lo iba a soltar todo / No sabe que la hombría / Nunca la aprendí en los cuarteles» (2013: 37). Esta idea se reproduce en la novela a través del personaje de Laura. Esta mujer (miembro del Frente, pero que, por sus costumbres, es asociada por la Loca a un militar) desconfía de que la Loca sea capaz de guardar secretos: «si no fuera por la inseguridad que sentían con él, esa tal Laura la dejaba botada ahí mismo» (2001: 178). Es el significante «homosexual» o «maricón» el que termina, para la sociedad, marcando al sujeto a través de una generalización que elimina lo particular: "¿Acaso ustedes no creen que hay gente como yo que puede guardar un secreto? ¿Creen que todos los maricones somos traicioneros?» (2001: 177). Así, el proceso de significar algo se realiza «a costa de anular las singularidades y diferencias en aras de la universalización necesaria» (de Santiago, 2000: 50). La sociedad se define a través de palabras que ya llevan una marca y no son cuestionadas. No se puede entrar a un mundo que no haya sido significado de forma previa. Para los militares o los comunistas, es la palabra la que define al sujeto y no viceversa: ninguno cuestiona el lenguaje, no se preguntan por lo que significa realmente el ser homosexual, ya que la carga inherente a este significante es definitoria. Y esto, tras la dictadura, no parece haber cambiado.

Entonces aparecen tres opciones para el sujeto. La primera es ocultar esa diferencia. Sumarse a la masa homogénea que oprime la individualidad, y callar aquello que es rechazado. En este punto aparece el personaje de Gonzalo, cuya homosexualidad nunca se explicita en la novela, pero se sugiere. Sobre él, que está basado en el estilista Gonzalo Cáceres, Lemebel tiene una crónica, en la que señala que «reiteraba y dejaba tan claro como la nieve de los Andes que no era homosexual. Más bien asexuado, por eso no tenía problemas para adaptarse a los cambios políticos» (2013: 154). Así entonces, se eliminaba la diferencia, y podía ser aceptado tanto por la izquierda como por la derecha: ya no tenía el significante «maricón» marcado en la espalda. Una segunda opción es asumir posiciones que tomen la diferencia y la sumen a esos espacios de poder, donde aparece la idea de lo "gay». Esta es la homosexualidad que, con los años, empieza a ser aceptada en cuanto adopta una forma de expresión que no incomoda, ya que no marca su diferencia. El mismo autor chileno expresa que lo «gay se suma al poder, no lo confronta, no lo transgrede. Propone la categoría homosexual como regresión al género. Lo gay [...] asiente y acomoda su trasero lacio en los espacios coquetos que le acomoda el sistema» (2013: 167). No sería una vindicación de la diferencia que desafíe los esquemas sociales, sino una suma a alguna de las dos perspectivas posibles que conforman la estructura. En el caso de la novela aparece el personaje de Lupe, quien se define como una persona de derecha porque

decirlo daba distinción. Era elegante ser de derecha y pronunciarlo fuerte con la mandíbula caída en medio de todas esas locas cabeza de papa que iban a la disco. Porque de todas no se hace una, todas son iguales, viven pendientes del corte de pelo, del cinturón, de la polerita que se van a poner el sábado para 
ir a zangolotearse a la disco, donde se manosean y atracan entre ellas como los gays de Estados Unidos (Lemebel, 2001: 114).

Así, lo gay se suma a un discurso repetido que coarta la posibilidad de subvertir y ejercer una individualidad fuera de la dicotomía que cataloga a los sujetos, por lo que se transforma en una categoría que no desafía ni la lógica ni el lenguaje imperante.

La tercera opción es la que resulta, probablemente, más difícil. Es tomar la perspectiva de lo neutro en el sentido que proclama Barthes: «Defino lo Neutro como aquello que desbarata el paradigma [...] ¿Qué es el paradigma? Es la oposición de dos términos virtuales» (2004: 51). Implica no entrar en ninguna de las posibilidades que la sociedad entrega, pero no bajo la idea de la indiferencia o de lo apolítico, sino como una posición reivindicativa, como una actividad que resulta intensa y potente. Esta idea de, como lo llama el autor francés, una elección desplazada, es finalmente una «manera de buscar libremente- mi propio estilo de presencia en las luchas de mi tiempo» (2004: 53). Aquí entra en juego, también, la tarea deconstructiva de Derrida, que en el ámbito filosófico implica inquietarse y dudar: «Inquietarse por los conceptos fundadores de toda la historia de la filosofía, des-constituirlos [...] Es, sin duda, y a pesar de las apariencias, la manera más audaz de esbozar un paso fuera de la filosofía» (1989: 390). Aquello en lo que se funda el paradigma, el dualismo en que se inserta una sociedad no es un origen invariable, no es una presencia eterna. Es una lectura que puede desbaratarse a través de una idea que se ha señalado a lo largo de este trabajo: el juego. Así, la tarea deconstructiva implicaría «la afirmación gozosa del juego del mundo y de la inocencia del devenir, la afirmación de un mundo de signos sin falta, sin verdad, sin origen, que se ofrece a una interpretación activa» (Derrida, 1989: 400). Todo se convierte en un sistema que no se cierra hacia un centro que lo estructura, sino que se encuentra siempre en un sistema de diferencias, en el que el juego se puede extender hasta el infinito.

Esta es la opción que toma Lemebel. Contra la idea de sumarse a uno de los dualismos que la sociedad impone a los sujetos, él entiende que para matar a la dictadura hay que matar el lenguaje que esta estructuró y legó a los años posteriores. Así, por ejemplo, la idea de marxismo que se fraguó en esos años es una que a él le resulta apática, más allá de tener pensamientos similares. En su manifiesto lo expresa de forma clara: "Yo no voy a cambiar por el marxismo / Que me rechazó tantas veces / No necesito cambiar / Soy más subversivo que usted» (Lemebel, 2013: 38). En ese resistirse a un cambio que lo adapte al paradigma, en esa proclamación de lo subversivo de su reivindicación homosexual, de loca, está el intento por desbaratar ese centro que obvia su presencia. En la novela, Carlos le dice a la Loca que podría ir a la universidad, que él conoce homosexuales en esos espacios. La respuesta es contundente: "Los maricones pobres nunca van a la universidad, lindo. Pero yo conozco muchos homosexuales que estudian en la universidad. ¿Y se les nota? ¿Son locas fuertes como yo, por ejemplo?» (Lemebel, 2001: 130). Su sexualidad no será callada. Esa es su lucha. A través de su lenguaje, de la transformación que lleva a cabo con todos los procedimientos ya señalados, establece su batalla contra un país cerrado en un dualismo que le ha obligado a hablar y soñar en voz baja. «Para la posición militante de Lemebel, el homosexual no es solo un personaje, sino la reconstrucción de una identidad compleja, en constante lucha» (López, 2011: 83). La Loca es, entonces, un personaje en permanente construcción, que está siempre escribiéndose y no deja catalogarse dentro de esquemas cerrados y estáticos. 


\title{
4. Conclusiones
}

La crítica a procesos sociales a través de la literatura ha adoptado muchas caras. Sin embargo, hay algunas, como la poesía social o la novela naturalista, en que lo principal reside dentro de la temática tratada: importa de lo que se habla, más que la manera. En otra línea aparecen aquellos que revolucionan la forma, que se preocupan del tratamiento del lenguaje porque entienden que desde ahí puede nacer una crítica más sustancial a lo que esa misma sociedad proclama. Es en esta tradición donde aparece Tengo miedo torero: a través de sus metáforas, de sus proliferaciones, de su mezcla de registros inventa una forma de concebir al sujeto que va más allá de los discursos estructurados dentro del país en el que él vive. Contra una lengua adormecida, cuya vida se quiere coartar desde las paredes que prometen un futuro de libertad, aparece Lemebel desatando al lenguaje de sus amarras; liberando y reivindicando su posibilidad de ser realmente creador, de hacer nacer nuevas subjetividades que escapen a aquellas que se niegan a sí mismas para tener una cabida en el entramado social. En un Chile que siguió viviendo con una constitución y un modelo económico nacido en dictadura, el neobarroco aparece como una fuente de rebeldía irreverente. El mismo Sarduy señala que traer el barroco desde los tiempos lejanos es una reivindicación política:

\begin{abstract}
¿Qué significa hoy en día una práctica del barroco? ¿Cuál es su sentido profundo? ¿Se trata de un deseo de oscuridad, de una exquisitez? Me arriesgo a sostener lo contrario: ser barroco hoy significa amenazar, juzgar y parodiar la economía burguesa, basada en la administración tacaña de los bienes, en su centro y fundamento mismo (1974: 99).
\end{abstract}

Así, se estructura a través del lenguaje literario otra forma de hacer política que cuestione las mismas bases en las que se sostiene todo un sistema que somete a los sujetos, que lo encierra en sus conceptos.

Nace una falla en el pensamiento. Un pequeño quiste que comienza a cuestionar, paulatinamente, aquellas palabras que se habían fosilizado. Ese trabajo, sin embargo, es largo y requiere a veces de generaciones. Pero el arte puede ser un primer paso. «Del arte se puede pasar más fácilmente a una ciencia filosófica verdaderamente liberadora» (Nietzsche, 1998: 61). Y ese es el legado que Lemebel entrega a la sociedad. Un primer paso, un grito desgarrado de loca, pero que no nace desde el llanto derrotista, sino desde la rabia, desde una fuerza demoledora que amenaza los ideales liberales cuya finalidad parece cerrar las puertas a la diferencia. El eco de ese grito sigue resonando después de la muerte del escritor. Seguirá resonando hasta que esa presencia, ese supuesto origen sea mostrado como lo que es: un lugar que se encuentra en disputa. Ese eco seguirá resonando hasta que, como el mismo poeta demanda, llegue la revolución que les entregue a aquellos pájaros heridos, encerrados y maltrechos, un pedazo de cielo rojo para que vuelen gritando en su locura desatada una nueva posibilidad de mundo.

\footnotetext{
Notas

${ }^{1}$ Movimiento de resistencia armado, asociado a la extrema izquierda. Se adjudicó el fallido atentado al dictador.

${ }^{2}$ En el caso del español de Chile, este es un proceso que se realiza bastante. Por ejemplo, la expresión (que aparece en la novela de Lemebel) "colipata» es popular en el país, tanto así que incluso aparece en la RAE como forma coloquial chilena para referirse al homosexual.
} 
${ }^{3}$ Chilenismo tradicional. Cuando una palabra termina en «ante», se responde «Venga el burro y te lo plante».

${ }^{4}$ La misma Loca hace esta reflexión de forma explícita. Cuando se da cuenta de que Carlos no es el verdadero nombre de su enamorado, comienza un proceso de deconstrucción de sus propias letras. Aparece ahí la idea de lo ilusorio que puede llegar a ser un nombre en su relación con la realidad. Ella había logrado conocer al sujeto, al cuerpo, a pesar de no saber su nombre. "Carlos-Carlo-Carl. Aquel nombre falso, disperso en la súplica chamullera de esas letras, un nombre de mentira» (Lemebel, 2001: 161).

${ }^{5} \mathrm{Si}$ bien "pico» puede haber nacido desde una perspectiva metafórica, esta se encuentra cristalizada ya como forma informal para referirse al miembro masculino. Es, por mucho, la forma más utilizada en la población chilena.

${ }^{6}$ El mismo autor señala esto en el prólogo de Tengo miedo torero. 


\section{Bibliografía citada}

BARTHES, R. (1970): «Escribir: ¿verbo intransitivo?» en Macksey, R. y Donato, E. (ed.), Los lenguajes críticos y las ciencias del hombre. Controversia estructuralista, Barcelona: Barral Editores, 1970.

BARTHES, R. (2004): Lo neutro, México: Siglo XXI.

BIANCHI, S. (2015): «Del neobarroco o la inestabilidad del taco alto (¿un neobarroco chilensis?)», Revista chilena de literatura, 89, 323-333

BOTTINELLI, A (2016). «Narrar (en) la 'post': La escritura de Álvaro Bisama, Alejandra Costamagna, Alejando Zambra», Revista chilena de literatura, 92, 731.

CID, J. (2017): «Vasos comunicantes del neobarroco: sobre las escenas y sentidos compartidos entre las obras de Néstor Perlongher y Pedro Lemebel», Acta Literaria, 55, 51-67

DE SANTIAGO, L (2000): «El poder de la palabra. Nietzsche y la retórica» en Nietzsche, F., Escritos sobre retórica, Madrid: Trotta.

DELEUZE, G. (1989): El pliegue. Leibniz y el Barroco, Barcelona: Paidós.

DERRIDA, J. (1989): La escritura y la diferencia, Barcelona: Anthropos.

GUERRERO, G. (1987): La estrategia neobarroca, Barcelona: Edicions del Mall. HEIDEGGER, M. (2009): Ser y tiempo, Madrid: Trotta.

LEMEBEL, P. (2001): Tengo miedo, torero, Barcelona: Anagrama.

LEMEBEL, P. (2013): Poco hombre: Crónicas escogidas, Santiago: Ediciones Universidad Diego Portales.

LEMEBEL, P. [Sebastián Quezada]. (2018). Off the record - Pedro Lemebel [Archivo de video]. Recuperado de< https://www.youtube.com/watch?v=NHLBRc3RDmA>.

LÓPEZ, B. (2011): "La construcción de "La loca" en dos novelas chilenas: El lugar sin límites de José Donoso y Tengo miedo torero de Pedro Lemebel», Acta Literaria, 42, 79-102.

NIETZSCHE, F. (1998): Humano, demasiado humano, Madrid: Edaf.

NIETZSCHE, F. (2000): Escritos sobre retórica, Madrid: Trotta.

NIETZSCHE, F. (2001): Sobre verdad y mentira en sentido extramoral, Madrid: Tecnos.

NIETZSCHE, F. (2019): El ocaso de los ídolos, Barcelona: Austral.

PÉREZ, C. (2019): «Reficcionalizar la crueldad: teatralización y travestismo en Tengo miedo torero de Pedro Lemebel», Revista chilena de literatura, 99, 303316.

RICHARD, N. (2001). Residuos y metáforas (Ensayos de crítica cultural sobre el Chile de la transición), Santiago: Cuarto propio.

ROSA, N. (1992): Artefacto, Rosario: Beatriz Viterbo Editora.

ROSA, N. (2006): Relatos críticos, Buenos Aires: Santiago Arcos Editor.

SARDUY, S. (1974): El barroco, Buenos Aires: Sudamericana, 1974.

SARDUY, S. (1977): «El barroco y el neobarroco" en Fernández Moreno, C. (coord.), América Latina en su literatura, México: Siglo Veintiuno, 167-184.

WASEM, M. (2010): «Neobarrosos en contexto: genealogías y debates de una movida poética", Literatura argentina siglo XX. De Alfonsín al Menemato, vol. 8, 216-229. 